\title{
Research loses in hasty changes to medical training
}

SIR - The new system for specialist medical training currently being implemented by the UK government will have dire consequences for the country's biomedical research. The modernizing medical careers (MMC) framework for training doctors comprehensively fails to recognize the importance of academic research in either the recruitment or the training of future medical consultants. Many young, ambitious UK clinicians engaged in full-time pre- and postdoctoral research recently discovered, to their horror, that their academic and research achievements were essentially dismissed as irrelevant in the new selection process for specialist training.

In many specialities, research has traditionally been an integral, if informal, constituent of becoming a senior hospital consultant. Under the new system, unless doctors decide at the very beginning of their careers to embark on a separate, dedicated academic pathway of medical training, they will have almost no exposure or opportunity to engage in research.

This is a serious mistake. Proleptically dismissing a research-experienced medical workforce will be of substantial detriment to clinical-science research, medical innovation and the development of scientific and economic partnerships with industry. It neglects the fact that many consultants who are employed fulltime in a purely clinical capacity frequently actively engage in research, often in collaboration with basic scientists and biomedical research companies. This provides mutual benefit to both clinical science and the provision of basic medical care. Furthermore, it overlooks the fact that many leading medical academics do not develop or discover their passion for research until more advanced stages of their training. If tomorrow's clinicians have no expertise in research, the invaluable and profitable alliance between clinical and academic medicine in the United Kingdom is in jeopardy.

This problem has suddenly become rather urgent, as the new system was introduced with such speed and opaqueness that few saw it coming. The rushed and chaotic implementation should be immediately suspended in favour of an open, balanced and broad debate on the future of medical training and research.

\section{Ben Seymour}

The Wellcome Trust Centre for Neuroimaging, University College London, and the National Hospital for Neurology and Neurosurgery, 12 Queen Square, London WC1N 3BG, UK

\section{Confidentiality is essential in misconduct inquiries}

SIR - Your News story "Misconduct? It's all academic..." (Nature 445, 240-241; 2007) and related articles in the same issue were too eager to find fault with the process universities use to deal with allegations of misconduct in research. As provost (S. M.) and vice president for research (C. R.) of Purdue University, we consider that you failed to give readers a true picture of the realities of these investigations.

A glaring omission is the fact that the US Department of Health and Human Services' integrity guidelines require US institutions to protect "the confidentiality of respondents, complainants, and research subjects" when investigating allegations of misconduct. This confidentiality is inconvenient for journalists. It also is extremely challenging for scientists and administrators who face the unhappy task of judging the integrity of one of their colleagues, but it is necessary if we are to prevent the ruin of good reputations through malicious or erroneous claims.

The process is not perfect. Like the US system of justice, it is frustrating, confusing and tedious, but it is the process we have, and we must follow it carefully until we find a better one. Despite its imperfections, in the end, it usually does the right thing. The process works best when those alleging misconduct document their concerns thoroughly and cooperate fully with all aspects of the inquiry - including the requirement for confidentiality.

An inquiry into a research misconduct allegation is not an inquiry into the verifiability of a research claim. Verifiability is decided by experimentation and debate, and often takes time to resolve. There can be legitimate differences of opinion regarding a laboratory observation. The Purdue administration's job is not to decide among such opinions.

Purdue University's policy on research integrity states: "The mere suspicion or allegation of wrongdoing, even if totally unjustified, is potentially damaging to a person's career. Consequently, no information about charges of a lack of integrity in research may be disclosed except to the appropriate university and federal authorities." Any response to an allegation of misconduct at Purdue will adhere to the letter and the spirit of that principle. We believe this is true at the vast majority of universities. Readers of Nature would not understand that truth from your coverage, nor would they be likely to conclude that a successful and fair inquiry might include a finding of 'not guilty'. Sally Mason, Charles Rutledge Purdue University, 610 Purdue Mall, West Lafayette, Indiana 47907-2040, USA

See News story, page 480 .

\section{New species show how little we know of the sea}

SIR - Your News Feature "Killer in the kelp" (Nature 445, 703-705; 2007) on the killer whale, Orcinus orca, states that the genetic analyses of type-C killer whales in Antarctic waters could lead to the naming of the first new whale species since 2003. However, the killer whale is actually a dolphin species belonging to the family Delphinidae, which includes about 30 species of small and mid-sized odontocetes (toothed whales, dolphins and porpoises).
Even if the type-C Antarctica killer whales were to be named a new species, they would still not become the first new cetacean species since Balaenoptera omurai was discovered in 2003. In 2005, a new dolphin species, the Australian snubfin dolphin Orcaella heinsohni (Cetacea, Delphinidae), was described by a team of scientists from Australia and the United States (I. Beasley et al. Mar. Mammal Sci. 21, 365-400; 2005). Genetic and osteological analyses of Irrawaddy dolphin specimens collected from Asian and Australian waters provided significant statistical basis that the Australian specimen was a new species.

In addition, a new species of beaked whale, Perrin's beaked whale Mesoplodon perrini (Cetacea, Ziphiidae), was described in 2002, on the basis of five animals stranded on the coast of California between 1975 and 1997 (M. L. Dalebout et al. Mar. Mammal Sci. 18, 577-608; 2002). Therefore, if the type-C Antarctica killer whale is recognized as a new species, it will become the first new dolphin species named since 2005, or the third new cetacean species since 2002 .

The discovery of three, potentially four, new cetacean species in the first decade of the twenty-first century underscore how little we know about these large mammals of the sea. It is very likely that more new species of whales and dolphins will be discovered and described in the years to come, as more rigorous morphological and genetic investigation are being conducted.

Shane Guan

Office of Protected Resources,

National Marine Fisheries Service,

Silver Spring, Maryland 20910, USA

Contributions to Correspondence may be submitted to corres@nature.com. 